\title{
Characteristics of thermal behavior of photoluminescent copolymers studied by the TG/DTG/FTIR coupled method
}

\author{
Beata Podkościelna ${ }^{1} \cdot$ Magdalena Sobiesiak $^{1}$
}

Received: 29 October 2015/Accepted: 23 March 2016/Published online: 11 April 2016

(c) The Author(s) 2016. This article is published with open access at Springerlink.com

\begin{abstract}
Thermal properties of the photoluminescent copolymers, naphthalene-2,7-diol dimethacrylate derivatives, are presented in this paper. The materials were synthesized by bulk copolymerization of 2,7-(2-hydroxy-3methacryloyloxypropoxy)naphthalene (2,7-NAF.DM) with four popular vinyl monomers: 2-hydroxyethyl methacrylate (HEMA), butyl acrylate (BA), divinylbenzene (DVB) and styrene (ST). As an initiator, the $\alpha, \alpha^{\prime}$-azoiso-bis-butyronitrile was used. Thermal stabilities and degradation behaviors of the obtained copolymers were studied by means of the differential scanning calorimetry and thermogravimetric (TG/DTG, in air and in helium atmosphere) analyses. Gases evolved during the thermal treatment were monitored using the TG-FTIR coupled method. The presented copolymers can have potential application as luminophores, protective coatings or fiber-optical sensors.
\end{abstract}

Keywords Photoluminescence $\cdot$ Naphthalene-2,7-diol · Thermal properties $\cdot$ Copolymerization

\section{Introduction}

Recently, development of polymeric-based photoluminescent materials has been observed. Such materials can be used as information displays in electrophotography, lighting, X-ray intensification and scintillation or for solar energy conversion [1-5].

Beata Podkościelna

beatapod@poczta.umcs.lublin.pl

1 Department of Polymer Chemistry, Faculty of Chemistry, Maria Curie-Skłodowska University, M. Curie Skłodowska Sq. 5, 20-031 Lublin, Poland
Aromatic polyesters, especially aromatic polymethacrylates, are commonly characterized by high thermal stability, very good mechanical properties as well as high visible-light transparency [6], whereas good luminescent properties are characteristic of compounds having aromatic rings, e.g., naphthalene. Combination of these properties provides possibilities of obtaining monomers with unique properties and capable of reaction polymerization.

Naphthalene derivatives are commonly used as a luminescent material due to their intense fluorescence, strong $\pi$ stacking and good chemical and thermal stabilities [7]. These properties make the naphthalene derivatives very useful precursors for preparation of: fluorophores of luminescent materials $[8,9]$, polymer light-emitting diodes $[10,11]$ and organic semiconductors [12-14].

According to Mori and Kijima, solid crystals of naphthalenes are semiconducting materials usually exhibiting intense photoluminescence. This phenomenon is associated with the $\pi$-electronic interactions of the molecular stacks. 2-Phenylnaphthalene derivatives (liquid crystalline naphthalenes) have been used as a switchable organic semiconductor [15]. The naphthalene unit has been applied as an ingredient of $\pi$-conjugated copolymers. The main objective was development of an emissive material in organic light-emitting diodes [16].

Studies on the synthesis of a new naphthalene monomer started with suspension-emulsion polymerization of 2,7NAF.DM with DVB. As a result, polymeric microspheres for the HPLC column were obtained [17]. Further studies dealt with the bulk polymerization of 2,7-NAF.DM with $N$ vinyl-2-pyrrolidone and determination of thermomechanical properties of the obtained copolymers [18]. Then, the research focused on the phenomenon of photoluminescence present in the monomer 2,7-NAF.DM and its copolymers 
with different commercial monomers [19, 20]. Current studies deal with thermal stability of the obtained copolymers under oxidative and inert (helium) conditions. In the case of these materials, thermal properties are important because they contribute to new application.

This paper presents, synthesis and thermal properties of photoluminescent copolymers dimethacrylate derivatives of naphthalene-2,7-diol with vinyl monomers (HEMA, BA, DVB and ST). $\alpha, \alpha^{\prime}$-Azoiso-bis-butyronitrile (AIBN) was used as an initiator. Chemical structure of the materials was characterized by the ATR-FTIR spectra. As compounds used as comonomers have different chemical structures (aromatic: DVB, ST and aliphatic: BA, HEMA), the effects of the comonomers structure on the physicochemical properties of the obtained product were investigated.

\section{Experimental}

\section{Materials}

2-Hydroxyethyl methacrylate, butyl acrylate, divinylbenzene and styrene were from Fluka AG (Buchs Switzerland). $\alpha, \alpha^{\prime}$-Azoiso-bis-butyronitrile (AIBN) was purchased from Merck (Darmstadt, Germany). Synthesis of 2,7-(2hydroxy-3-methacryloyloxypropoxy)-naphthalene (2,7NAF.DM) was presented in the previous paper [17].

\section{Preparation of compositions}

The compositions consisting of 2,7-NAF.DM, one of vinyl monomers (HEMA, BA, DVB or ST) and an initiator (AIBN) were obtained. For all compositions, the constant mass ratio of 2,7-NAF.DM to vinyl monomers (1: $10 \mathrm{w} / \mathrm{w})$ was applied. After dissolving, the monomers and the initiator $(0.5 \%)$ were added and the composition was put into a glass mold.

Next, the molds were moved into a water bath for $12 \mathrm{~h}$ at $60{ }^{\circ} \mathrm{C}$, and finally, the reaction was continued in the heating chamber for $4 \mathrm{~h}$ at $100{ }^{\circ} \mathrm{C}[19,20]$. For comparison, physicochemical properties of the homopolymer (2,7NAF.DM-HOMO) were also determined.

\section{Characterization}

Absorption spectra for 2,7-NAF.DM solutions (in methanol) were obtained using the UV-Vis spectrophotometer (UV-1800 Shimadzu).

The thermogravimetric analysis (TG) was performed using a MOM 3427 derivatograph (Paulik, Paulik and Erdey, Budapest, Hungary) in the temperature range of ${ }^{20}-1000{ }^{\circ} \mathrm{C}$, in the air atmosphere. The heating rate was $10{ }^{\circ} \mathrm{C} \mathrm{min}{ }^{-1}$. The mass sample was $100 \mathrm{mg}$. The thermal stability factors such as loss mass temperatures $\left(T_{5 \%}, T_{20 \%}\right.$, $\left.T_{50 \%}\right)$, decomposition temperatures $\left(T_{1}, T_{2}, T_{3}\right)$ and final decomposition temperature $\left(T_{\mathrm{f}}\right)$ were estimated.

TG/DTG curves were obtained with the use of a thermal analyzer STA 449 F1 Jupiter (Netzsch, Selb, Germany). All measurements were taken in the $\mathrm{Al}_{2} \mathrm{O}_{3}$ crucible with the sample mass $\sim 7 \mathrm{mg}$ under helium atmosphere $\left(40 \mathrm{~mL} \mathrm{~min}^{-1}\right)$. Dynamic scans were performed at the heating rate of $10^{\circ} \mathrm{C} \mathrm{min}^{-1}$ in the temperature range 30-1000 ${ }^{\circ} \mathrm{C}$. Gaseous products evolved from the sample at the time of heating were analyzed simultaneously by the online coupled Fourier transform infrared spectrometer FTIR Tensor 27 (Bruker).

Differential scanning calorimetry (DSC) curves were obtained with the use of a DSC Netzsch 204 calorimeter (Netzsch, Günzbung, Germany). The measurements were taken in the aluminum pans with a pierced lid with the sample mass $\sim 7 \mathrm{mg}$ under nitrogen atmosphere $\left(30 \mathrm{~mL} \mathrm{~min}^{-1}\right)$. Dynamic scans were performed at a heating rate of $10^{\circ} \mathrm{C} \mathrm{min}^{-1}$ in the temperature range $20-500{ }^{\circ} \mathrm{C}$. Glass transition temperature and curing characteristics, such as temperature of the peak maximum and final cure temperature, were determined.

ATR-FTIR (attenuated total reflectance) spectra were obtained using a Bruker FTIR spectrophotometer TENSOR 27 equipped with diamond crystal. The spectra were recorded in the range of $600-4000 \mathrm{~cm}^{-1}$ with a resolution of $4 \mathrm{~cm}^{-1}$ and 32 scans.

\section{Results and discussion}

\section{ATR-FTIR analysis}

The chemical structures of the monomers are shown in Fig. 1. The ATR-FTIR spectra for the homopolymer and all copolymers are presented in Fig. 2. Characteristic bands of the functional groups are visible on the curves. In the<smiles></smiles><smiles>C=CC(=O)OCCCCC</smiles><smiles>C=Cc1ccc(C=C)cc1</smiles>

Fig. 1 Chemical structures of the monomers used 
Fig. 2 ATR-FTIR spectra of the presented copolymers

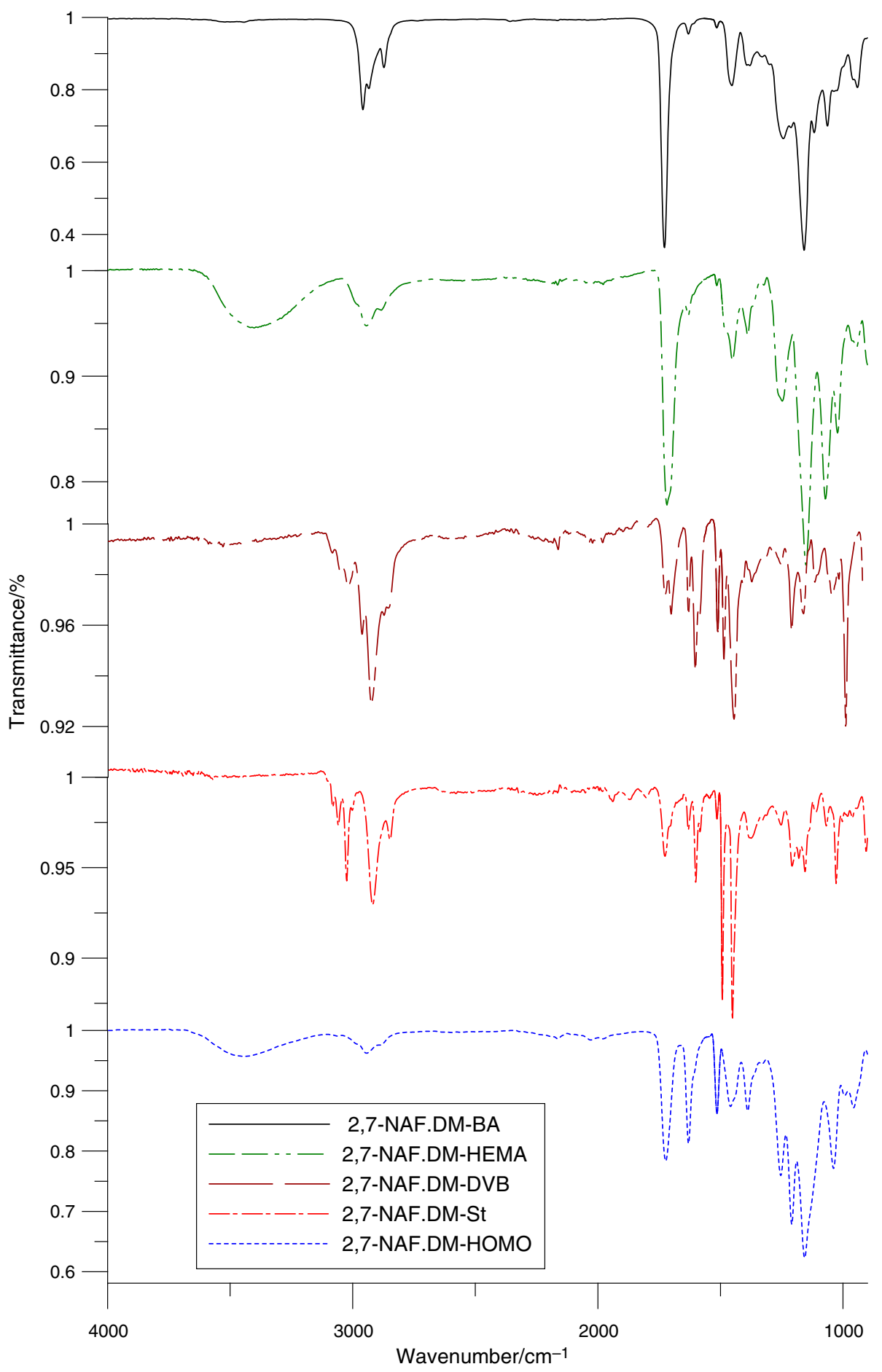

spectrum of 2,7-NAF.DM-HEMA and 2,7-NAF.DMHOMO, the signals at $3250-3600 \mathrm{~cm}^{-1}$ corresponding to the aliphatic $\mathrm{OH}$ groups can be seen. The $\mathrm{C}-\mathrm{H}$ stretching vibrations of the methylene and methyl groups are observed at 2850-2990 $\mathrm{cm}^{-1}$. Analogous stretching vibrations of $\mathrm{C}-\mathrm{H}$ bonds for aromatic rings give signals in the range of $3000-3100 \mathrm{~cm}^{-1}$. A sharp signal at
$1730 \mathrm{~cm}^{-1}$ corresponding to the carbonyl groups is found on all curves. Additionally, aromatic ring vibrations for the aromatic comonomers (ST, DVB) at $1500-1600 \mathrm{~cm}^{-1}$ are visible. Characteristic signals of vinyl bonds vibrations in the DVB copolymer are present at 901 and $988 \mathrm{~cm}^{-1}$, which indicates that some of these groups are still unreacted. 


\section{Absorption spectra}

Absorption spectra for 2,7-(2-hydroxy-3-methacryloyloxypropoxy)naphthalene solutions are presented in Fig. 3. In these spectra, the absorption band typical of 2,7NAF.DM can be seen at $400-500 \mathrm{~nm}$ with the maximum at $450 \mathrm{~nm}$. This spectrum is connected with 2,7 linkage at the naphthalene dimethacrylate substitutes because in isomers of naphthalene $(2,3$ or 1,5$)$, photoluminescence is not observed. This phenomenon is also visible at 2,7-NAF.DM copolymers. After excitation, the polymer emits yellowgreen radiation (Fig. 4) [18].

\section{TG/DTG analysis under oxidative conditions}

Thermal stabilities in air atmosphere of 2,7-NAF.DM copolymers were studied by means of thermogravimetry. The obtained data from the TG and DTG measurements are presented in Table 1. It can be seen that the temperature, at which $5 \%$ mass loss of the copolymers is found, ranges from 120 to $200{ }^{\circ} \mathrm{C}$. The final decomposition temperature $\left(T_{\mathrm{f}}\right)$ is in the range $560-720^{\circ} \mathrm{C}$. The DTG curves for some copolymers contain three separate degradation steps. The first decomposition peak is observed in the range $100-200{ }^{\circ} \mathrm{C}$ with the maximum of mass loss $\left(T_{1}\right)$ at $120-160{ }^{\circ} \mathrm{C}$. The second decomposition stage takes place between 260 and $440{ }^{\circ} \mathrm{C}$ with the maximum of mass loss $\left(T_{2}\right)$ at $320-400{ }^{\circ} \mathrm{C}$, while the third peak is observed in the range $420-690{ }^{\circ} \mathrm{C}$ with the maximum of mass loss $\left(T_{3}\right)$ at $500-580{ }^{\circ} \mathrm{C}$.

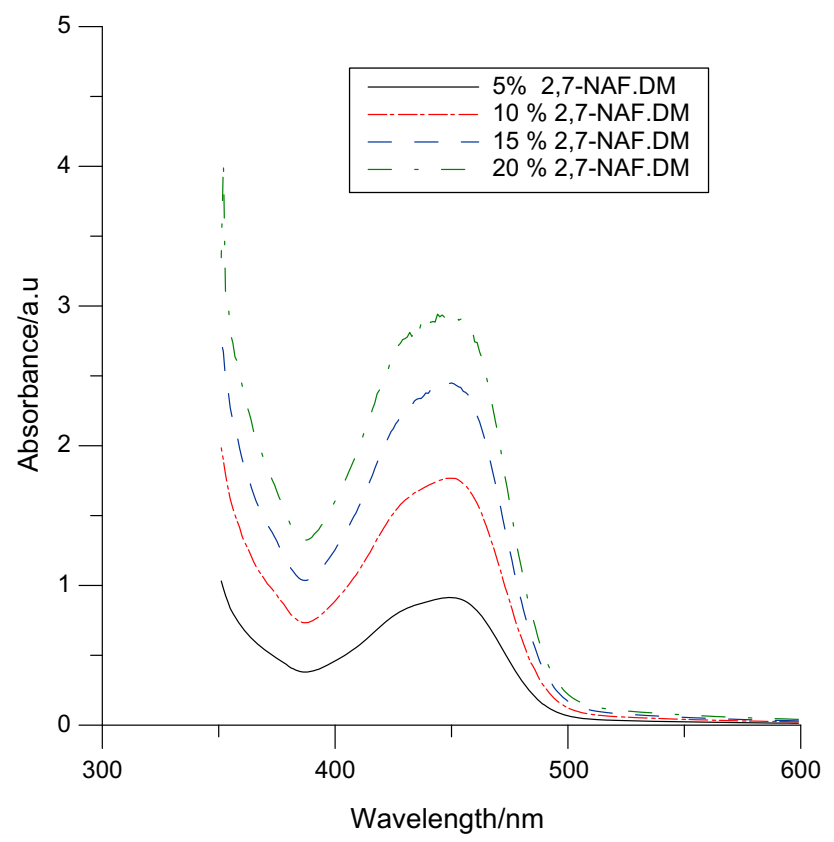

Fig. 3 Absorption spectra of 2,7-NAF.DM solutions
The first decomposition peak is associated with the removal of unreacted monomers, the second one with the partial decomposition and evaporation of volatile components, and the third is related to the total degradation of aromatic species of copolymers. According to the TG data analyses, the copolymer 2,7-NAF.DM-DVB is more thermally stable. Better thermal stability is a consequence of the presence of aromatic ring and cross-linking functionalities in a structure of divinylbenzene molecule.

For an overall assessment of the thermal properties of the obtained copolymers, the TG, DTG and DSC analyses in an inert (helium) gas were also conducted.

\section{TG/DTG results under inert conditions}

The TG and DTG curves are shown in Figs. 5 and 6. For the homopolymer, the decomposition process takes place in the range $286-525^{\circ} \mathrm{C}$ with the maximum decomposition temperature at $398{ }^{\circ} \mathrm{C}$ and the rate of the mass loss is $10.33 \% \mathrm{~min}^{-1}$.

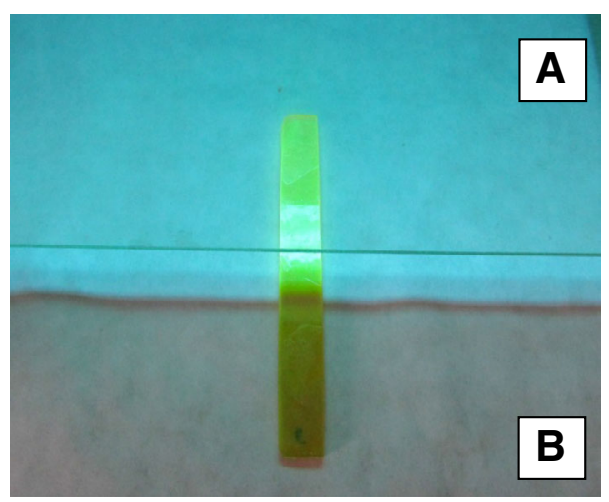

Fig. 4 Photography of the sample of copolymer (2,7-NAF.DM-ST) exposed (a) or not (b) to UV light

Table 1 Thermal stabilities of the studied copolymers in oxidative conditions

\begin{tabular}{llllllll}
\hline Copolymers & \multicolumn{1}{l}{ Temperature $/{ }^{\circ} \mathrm{C}$} \\
\cline { 2 - 8 } & $T_{5 \%}$ & $T_{20 \%}$ & $T_{50 \%}$ & $T_{\mathrm{f}}$ & $T_{1}$ & $T_{2}$ & $T_{3}$ \\
\hline 2,7-NAF.DM-BA & 200 & 380 & 400 & 600 & - & 400 & 540 \\
2,7-NAF.DM-HEMA & 120 & 260 & 300 & 560 & 120 & 320 & 500 \\
2,7-NAF.DM-DVB & 180 & 360 & 480 & 720 & 160 & 400 & 580 \\
2,7-NAF.DM-ST & 190 & 360 & 490 & 670 & - & 380 & 560 \\
2,7-NAF.DM-HOMO & 200 & 340 & 400 & 700 & - & 320 & 540 \\
\hline$T_{5 \%}, T_{20 \%}, T_{50 \%}$ - the rate of mass loss & & & & \\
$T_{1}, T_{2}, T_{3}$-the decomposition temperatures \\
$T_{\mathrm{f}}$-the final decomposition temperature
\end{tabular}




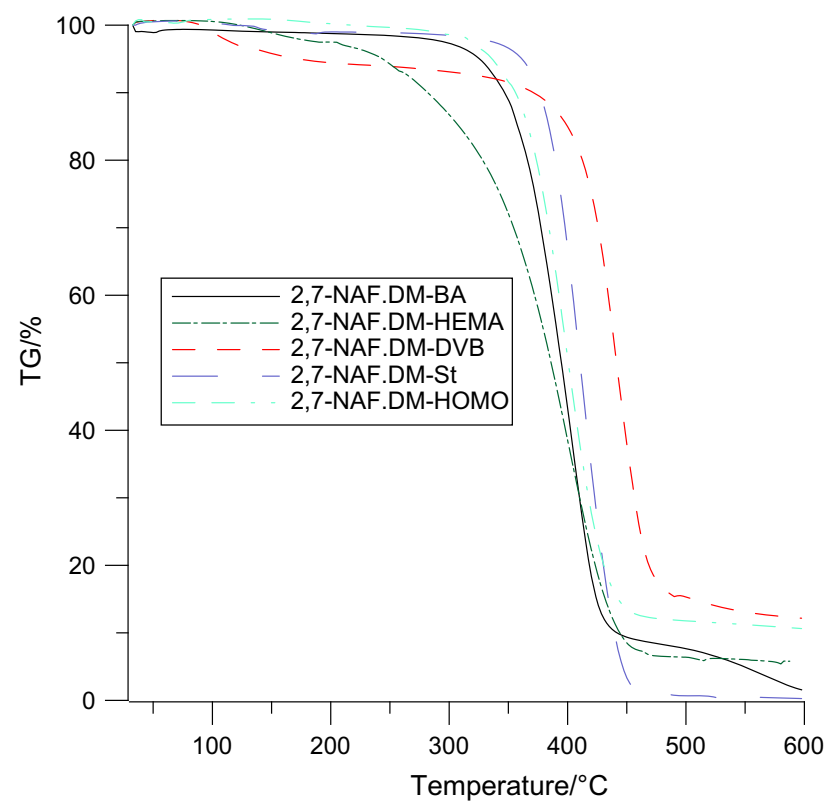

Fig. 5 TG curves of the studied materials in helium atmosphere

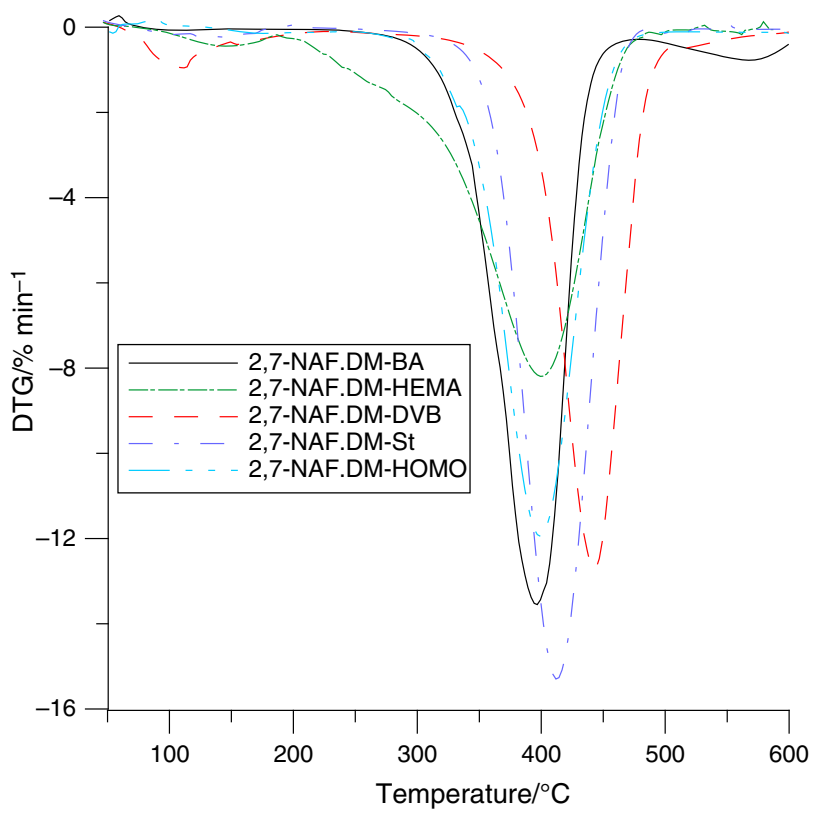

Fig. 6 DTG curves of the studied materials in helium atmosphere

For 2,7-NAF.DM copolymers with the aliphatic olefin compounds (HEMA and BA), the decomposition process proceeds almost in the same range. The maximum of the decomposition process takes place at $396{ }^{\circ} \mathrm{C}$ for the HEMA and BA copolymers. However, the rate of decomposition strongly depends on chemical structure of the comonomers. 2,7-NAF.DM-BA decomposes the most readily $\left(-13.3 \% \mathrm{~min}^{-1}\right)$ of the aliphatic comonomers. In the case of 2,7-NAF.DM-HEMA, thermal decomposition starts at a relatively low temperature (about $200{ }^{\circ} \mathrm{C}$ ) and proceeds slowly $\left(-7.7 \% \mathrm{~min}^{-1}\right)$ and gradually rises up to $500{ }^{\circ} \mathrm{C}$.

The usage of aromatic comonomers (ST and DVB) results in preparation of polymers of more thermally stable structure. For this reason, the maximum decomposition temperature is shifted to higher values: $412{ }^{\circ} \mathrm{C}$ for ST and $440{ }^{\circ} \mathrm{C}$ for DVB. However, the decomposition process for these materials is little faster than in case of homopolymer, and the values of decomposition rates are -15.30 and $-11.18 \% \mathrm{~min}^{-1}$, respectively.

Taking into account the rates of decomposition processes and the chemical structure of comonomers, it can be concluded that in the case of DVB and HEMA both double bonds and $\mathrm{OH}$ groups (respectively) are involved in creation of a highly cross-linked polymeric network, while the others probably form polymers of linear structure.

\section{Analysis of evolved gases}

Simultaneously to the TG experiments, the FTIR analysis of gases evolved by the samples was performed. The obtained results are presented in Fig. 7a, b. The released gaseous products that can be identified are as follows: $\mathrm{CO}_{2}$ (strong band at 2400-2240 and weak at 735-600 $\mathrm{cm}^{-1}$ ), $\mathrm{CO}$ (double band in the range $2240-2060 \mathrm{~cm}^{-1}$ ), $\mathrm{H}_{2} \mathrm{O}$ (signals in the ranges 4000-3300, 1875-1275 $\mathrm{cm}^{-1}$ ), acids (3600-3400, 1860-1650 and 1300-1000 $\mathrm{cm}^{-1}$ ), esters (signals at $3115-2675$ and $1855-1600 \mathrm{~cm}^{-1}$ ) and hydrocarbons (wide and strong band 3115-2675 and weaker $1500-1300 \mathrm{~cm}^{-1}$ ) [21, 22].

Chemical composition of gases emitted in the first stage of the mass loss up (to $200{ }^{\circ} \mathrm{C}$ ) for all materials, as it was mentioned above, consists of hydrocarbons, esters and acids. That indicates release of volatile monomers of acrylic and methacrylic acid derivatives. Essential differences in character of the spectra are observed for the temperatures, where destruction processes take place (Fig. 7a, b). Copolymers with aromatic comonomers (DVB and ST) release mainly aromatic hydrocarbons and small amounts of oxygen-containing organic aliphatic compounds. The main products of thermal destruction of homopolymer (HOMO) and copolymers with aliphatic comonomers (HEMA and BA) are acetic acid, aliphatic hydrocarbons, water and carbon dioxide. Additionally, a small amount of unsaturated organic acids (acrylic and methacrylic) is also evolved.

It is worth noting that very small amounts of water were given off due to heating the analyzed polymers. It means that condensation processes between the functional groups present in the polymeric structure have no significant effects before and during thermal destruction. 

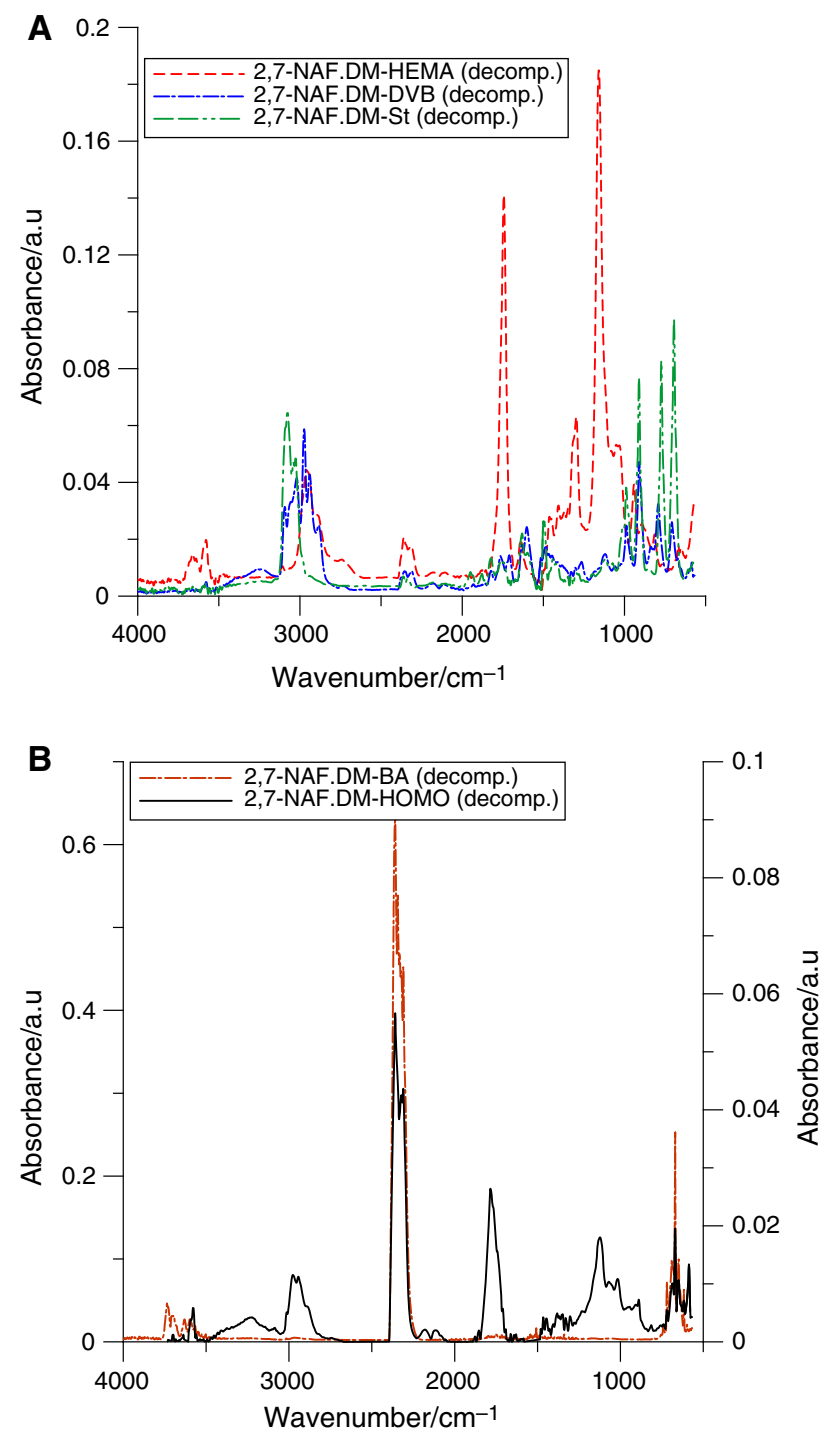

Fig. 7 a, b Absorbance spectra plots from the TG-FTIR analysis

Such way of destruction is a consequence of chemical structure of the copolymer. Oxygen functional groups present in the polymeric network mainly in the form of ester bonds (Fig. 2), introduced by (meth)acrylic monomers, easily decompose under heating.

\section{DSC analysis}

For overall studies of 2,7-NAF.DM copolymers, the DSC measurements were taken. The obtained results in the range from -100 to $250{ }^{\circ} \mathrm{C}$ are presented in Fig. 8. The endoand exothermic effects can be observed on the curves. The glass transition temperatures are for -50 to $-30{ }^{\circ} \mathrm{C} 2,7$ NAF.DM-BA, for $70-110^{\circ} \mathrm{C}$ 2,7-NAF.DM-HEMA, and for $80-120{ }^{\circ} \mathrm{C} 2,7-N A F . D M-S T$. It means that up to this temperature, the polymer maintains its glassy properties (toughness and stiffness). Endothermic peaks for the

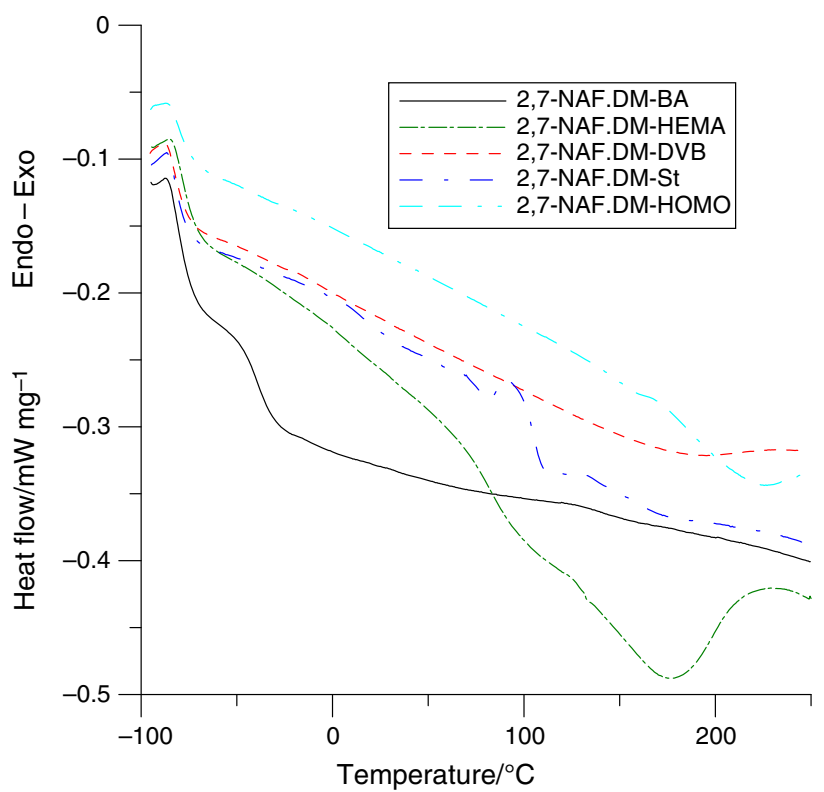

Fig. 8 DSC curves of the studied copolymers

HEMA and DVB copolymers $\left(100-200{ }^{\circ} \mathrm{C}\right)$ are the consequence of releasing of unreacted monomers, while the one for the homopolymer (above $175^{\circ} \mathrm{C}$ ) is a results of initial decomposition. The peak at over $200{ }^{\circ} \mathrm{C}$ with the exothermic effect corresponds to curing reaction in the DVB copolymer. The presence of curing peak is connected with the unreacted vinyl groups in DVB. This observation is in line with the ATR-FTIR spectra.

\section{Conclusions}

This article presented the thermal properties of four photoluminescent copolymers. The maximum of absorption for 2,7-NAF.DM solutions is observed at $450 \mathrm{~nm}$. The thermal resistance of the copolymers is closely related to the chemical structure of the used monomers. The copolymer cross-linked with divinylbenzene (DVB) was more thermally stable in both air and inert atmosphere.

In inert atmosphere, the maximum of decomposition process takes place at $396{ }^{\circ} \mathrm{C}$ for the HEMA and BA copolymers. The usage of aromatic comonomers (ST and DVB) results in preparation of polymers of more thermally stable structure $\left(412{ }^{\circ} \mathrm{C}\right.$ for ST and $440{ }^{\circ} \mathrm{C}$ for DVB). Chemical composition of gases emitted in the first stage of the mass loss up (to $200{ }^{\circ} \mathrm{C}$ ) for all materials consists of hydrocarbons, esters and acids. The glass transition temperatures are as follows: for 2,7-NAF.DM-BA -50 to $-30{ }^{\circ} \mathrm{C}, \quad 2,7-N A F . D M-H E M A \quad 70-110{ }^{\circ} \mathrm{C}$, and 2,7NAF.DM-ST $80-120^{\circ} \mathrm{C}$. The resulting copolymers are characterized by good thermal resistance and photoluminescent properties derived from 2,7-NAF.DM monomer. 
Acknowledgements The research leading to these results has received funding from the People Programme (Marie Curie Actions) of the European Union's Seventh Framework Programme FP7/20072013/ under REA Grant Agreement No. 608382.

Open Access This article is distributed under the terms of the Creative Commons Attribution 4.0 International License (http://crea tivecommons.org/licenses/by/4.0/), which permits unrestricted use, distribution, and reproduction in any medium, provided you give appropriate credit to the original author(s) and the source, provide a link to the Creative Commons license, and indicate if changes were made.

\section{References}

1. Hong JM, Cho HN, Kim DY, Kim CY. Synthesis and luminescence studies of poly(fluorenylene ethynylene)s. Synth Met. 1999;102:933-4.

2. Mikroyannidis JA. Synthesis and characterization of soluble, photoluminescent polyamides, polyesters and polyethers containing 9,10-di(4-biphenylyl)anthracene segments in the main chain. Polymer. 2000;41:8193-204.

3. Morisaki Y, Wada N, Chujo Y. Novel conjugated polymers containing [2.2] paracyclophane and carbazole units with efficient photoluminescence. Polym Bull. 2005;53:73-80.

4. Lee K-H, Morino K, Sudo A, Endo T. Synthesis and optical properties of $\pi$-conjugated polymers composed of diester-substituted bithiophene and dibenzothiophene or carbazole. Polym Bull. 2011;7:227-36.

5. Zuo Z, Li Y. Functional polymers for photovoltaic devices. Polym Bull. 2012;68:1425-67.

6. Liou G-S, Lin S-M, Yen H-J. Synthesis and photoluminescence properties of novel polyarylates bearing pendent naphthylamine chromophores. Eur Polym J. 2008;44:2608-18.

7. Mori T, Kijima M. Synthesis and electroluminescence properties of carbazole-containing 2,6-naphthalene-based conjugated polymers. Eur Polym J. 2009;45:1149-57.

8. Montalti M, Dolci LS, Prodi L, Zaccheroni N, Stuart MCA, van Bommel KJC. Energy transfer from a fluorescent hydrogel to a hosted fluorophore. Langmuir. 2006;22:2299-303.

9. Tomasulo M, Kaanumal SL, Sortino S, Raymo FM. Synthesis and properties of benzophenone-spiropyran and naphthalenespiropyran conjugates. J Org Chem. 2007;72:595-605.
10. Sannasi V, Sundararaj BG, Meenakshi S, Jeyakumar D. Synthesis, characterization and optical properties of poly $\left(4,4^{\prime}\right.$-dioctyloxy-3,3'-biphenylene vinylene) copolymers. Iran Polym J. 2011;20:633-44.

11. Huang F, Zhang Y, Liu MS, Cheng YJ, Jen AKY. High-efficiency and color stable blue-light-emitting polymers and devices. Adv Funct Mater. 2007;17:3808-15.

12. Oikawa K, Monobe H, Nakayama K, Kimoto T, Tsuchiya K, Heinrich B. High carrier mobility of organic field-effect transistors with a thiophene-naphthalene mesomorphic semiconductor. Adv Mater. 2007;19:1864-8.

13. Yasuda T, Kashiwagi K, Morizawa Y, Tsutsui T. Diethynyl naphthalene derivatives with high ionization potentials for p-channel and n-channel organic field-effect transistors. J Phys D Appl Phys. 2007;40:4471-5.

14. Lee Y-L, Hsu H-L, Chen S-Y, Yew T-R. Solution-processed naphthalene diimide derivatives as n-type semiconductor materials. J Phys Chem C. 2008;112:1694-9.

15. Mori T, Kijima M. Synthesis and optical properties of polynaphthalene derivatives. Opt Mater. 2007;30:545-52.

16. Funahashi M, Hanna J. Fast ambipolar carrier transport in smectic phases of phenylnaphthalene liquid crystal. Appl Phys Lett. 1997;71:602-4.

17. Podkościelna B, Gawdzik B. Influence of diluent compositions on the porous structure of methacrylate derivatives of aromatic diols and divinylbenzene. Appl Surf Sci. 2010;256:2462-7.

18. Podkościelna B. New photoluminescent copolymers of naphthalene-2,7-diol dimethacrylate and $N$-vinyl-2-pyrrolidone: synthesis, characterisation and properties. J Therm Anal Calorim. 2014;116:785-93.

19. Podkościelna B. Method of photoluminescence copolymers preparation. Pat. 2015; PL 402734.

20. Podkościelna B, Lipke A, Gawdzik B, Majdan M. Synthesis, characterization and luminescent properties of new copolymers of dimethacrylate derivatives of naphthalene-2,7-diol. Polym Adv Technol. 2015;26:176-81.

21. Bassilakis R, Carangelo RM, Wójtowicz MA. TG-FTIR analysis of biomass pyrolysis. Fuel. 2001;80:1765-86.

22. Yan JH, Zhu HM, Jiang XG, Chi Y, Cen KF. Analysis of volatile species kinetics during typical medical waste materials pyrolysis using a distributed activation energy model. J Hazard Mater. 2009;162:646-51. 